\title{
Total plasma homocysteine is associated with hypertension in Type I diabetic patients
}

\author{
S. Neugebauer ${ }^{1}$, L. Tarnow ${ }^{2}$, C. Stehouwer ${ }^{3}$, T. Teerlink ${ }^{4}$, T. Baba ${ }^{1}$, T. Watanabe ${ }^{1}$, H.-H. Parving ${ }^{2}$ \\ 1 Third Department of Internal Medicine, Fukushima Medical University, Fukushima, Japan \\ ${ }^{2}$ Steno Diabetes Centre, Gentofte, Denmark \\ ${ }^{3}$ Department of Internal Medicine, Academic Hospital Vrije University and Institute for Cardiovascular Research, \\ Vrije University, Amsterdam, The Netherlands \\ ${ }^{4}$ Department of Clinial Chemistry, Academic Hospital Vrije University, Amsterdam, The Netherlands
}

\section{Abstract}

Aims/hypothesis. Although hyperhomocysteinaemia and methylenetetrahydrofolate reductase gene polymorphism are accepted risk factors for cardiovascular disease, their association with micro angiopathy or blood pressure in diabetic patients is still being debated. This study explores the relation between plasma homocysteine concentrations, methylenetetrahydrofolate reductase gene polymorphism, hypertension, diabetic microvascular and macrovascular complications associated with kidney function.

Methods. Vascular complications, hypertension, methylenetetrahydrofolate reductase genotype (RFLP with Hinf I digestion), and total plasma homocysteine (HPLC) were investigated in 389 well-characterized Type I (insulin-dependent) diabetic patients with normal (GFR $\left.\geq 75 \mathrm{ml} \cdot \mathrm{min}^{-1} \cdot\left(1.73 \mathrm{~m}^{2}\right)^{-1} ; n=273\right)$, or impaired renal function $\left(\right.$ GFR $<75 \mathrm{ml} \cdot \mathrm{min}^{-1} \cdot\left(1.73 \mathrm{~m}^{2}\right)^{-1}$; $n=116)$.

Results. Patients with microvascular and macrovascular complications showed higher total plasma homocysteine concentrations than those without complica- tions. However, after the data for GFR (main determinant for plasma homocysteine) was adjusted we observed that plasma homocysteine concentrations greater than $8.6 \mu \mathrm{mol} / \mathrm{l}$ in patients with normal GFR are not related to vascular complications, but to hypertension $(8.6-11.3 \mu \mathrm{mol} / \mathrm{l}:$ OR 1.9 ; >11.3 $\mu \mathrm{mol} / \mathrm{l}:$ OR 3.7). The risk for coronary heart disease (CHD) was also enhanced by a plasma homocysteine concentration greater than $11.3 \mu \mathrm{mol} / \mathrm{l}$ (OR 5.9). Although the $\mathrm{T}$ allele was an independent determinant of plasma homocysteine, the methylenetetrahydrofolate reductase gene polymorphism was neither associated with diabetic vascular complications nor with hypertension. Conclusion/interpretation. Increased plasma homocysteine concentrations but not the $\mathrm{T}$ allele per se, enhance the risk of hypertension and of CHD in Danish Type I diabetic patients with normal renal function. [Diabetologia (2002) 45:1315-1324]

Keywords Type I diabetes, hypertension, homocysteine, methylenetetrahydrofolate reductase, gene polymorphism, vascular complications.
Received: 5 March 2002 / Revised: 27 May 2002

Published online: 8 August 2002

C Springer-Verlag 2002

Corresponding author: Dr. S. Neugebauer, Third Department of Internal Medicine, Fukushima Medical University, Hikarigaoka 1, 960-1295 Fukushima, Japan, E-mail: sneugeba@fmu.ac.jp Abbreviations: CVD, Peripheral, cardiovascular disease, and stroke; MTHFR, methylenetetrahydrofolate reductase; OR, odds ratio; tHcy, total plasma homocysteine; UAER, urinary albumin excretion rate; WHO, World Health Organization
The excess mortality in patients with Type I (insulindependent) diabetes mellitus is related to the development of diabetic nephropathy [1], which is associated with an increasing incidence of CHD, retinopathy and rising blood pressure. Epidemiological studies have shown that the risk and severity of those diabetic microvascular and macrovascular complications are strongly related to the duration of diabetes, poor glycaemic control, and hypertension. However, results of interventional trials indicated that intensified insulin treatment and antihypertensive therapy could not en- 
tirely prevent patients from death. Growing evidence suggests that further metabolic as well as inherited factors $[2,3]$ might be involved in the pathogenesis of diabetic vascular complications.

Mild hyperhomocysteinaemia which has emerged as a new independent risk factor for premature arteriosclerosis and cardiovascular disease [4] can be caused by methylenetetrahydrofolate reductase (MTHFR) deficiency, an inherited defect of the homocysteine metabolism. MTHFR, a cytoplasmatic enzyme, expressed by human vascular endothelium, acts in the remethylation pathway by which homocysteine is remethylated to methionine. A common mutation of the MTHFR gene, a cytosine (C) to thymidine (T) substitution at nucleotide 677 of the cDNA sequence (C677T), leads to the conversion of alanine to valine in the protein sequence [5]. This results in an enzyme with temperature-related loss of function, causing hyperhomocysteinaemia, and thus increased susceptibility for premature atherosclerotic disease in non-diabetic subjects [6]. It has been suggested that the MTHFR gene polymorphism also confers increased susceptibility to the microvascular complications of diabetic retinopathy $[6,7]$ and nephropathy $[8,9]$. However, only a few studies have addressed the association of MTHFR gene polymorphism and/or the tHcy concentration with diabetic nephropathy $[10,11]$, retinopathy $[7,10,11,12]$, and diabetic macrovascular $[11,13]$ complications, with conflicting results. This might be partially due to small study groups and methodological differences, but also due to the effect of impaired renal function (defined by creatinine clearance) on tHcy concentrations was not taken into account.

Increased tHcy concentrations were also suggested to be related to hypertension in non-diabetic patients $[14,15]$ also to mean blood pressure and to diastolic blood pressure in Type II (non-insulin-dependent) diabetic patients [16]. However, it has not been investigated yet, whether tHcy and/or MTHFR gene polymorphism have an additive effect on hypertension in diabetes mellitus.

This study investigated the relation between tHcy and GFR in patients with normal and with impaired renal function whether there is an association of tHcy concentrations with microvascular and macrovascular complications in Type I diabetic patients, and whether the MTHFR gene polymorphism can predict these complications. We also addressed whether high tHcy concentrations cluster with hypertension, the important risk factor which $\mathrm{CHD}, \mathrm{CVD}$, retinopathy, and nephropathy have in common.

\section{Subjects and methods}

Patients. Included in the case-control study were 318 Danish Type I diabetic patients attending the outpatient clinic at Steno Diabetes Center. Taking into account that tHcy might be influ- enced by kidney function [17] the patients were divided into two groups, one group with normal renal function $(n=273)$, and one group with impaired renal function $(n=116)$. Normal renal function was defined by a GFR greater than or equal to $75 \mathrm{ml} \cdot \mathrm{min}^{-1} \cdot\left(1.73 \mathrm{~m}^{2}\right)^{-1}$, the median value. Diabetic nephropathy $(n=198)$ was diagnosed clinically based on the following criteria: persistent albuminuria greater than $300 \mathrm{mg}$ per $24 \mathrm{~h}$ in at least two out of three consecutive 24-h urine collections, diagnosis of retinopathy and no other evidence of kidney or renal tract disease. Normoalbuminuria $(n=191)$ was defined as persistent urinary albumin excretion rate (UAER) of less than $30 \mathrm{mg}$ per $24 \mathrm{~h}$. The diagnosis of diabetic retinopathy was assessed in all but two patients by fundus photography after pupillary dilatation and graded: nil $(n=68)$, simplex $(n=166)$, or proliferative $(n=155)$ diabetic retinopathy. Patients were interviewed using the cardiovascular questionnaire of the World Health Organization (WHO). The diagnosis of hypertension $(n=197)$, CHD $(n=53)$ and CVD (peripheral, cardio- vascular disease, and strokes) ( $n=84)$ of all patients was carried out following the criteria of the WHO [18, 19]. Hypertensive patients were defined as patients on antihypertensive medication, or with a systolic blood pressure greater than $160 \mathrm{mmHg}$ or a diastolic blood pressure greater than $95 \mathrm{mmHg}$. Arterial blood pressure was measured twice and averaged, after at least $10 \mathrm{~min}$ of rest in the supine position. BMI was calculated as weight $(\mathrm{kg})$ divided by height $\left(\mathrm{m}^{2}\right)$. The experimental design was approved by the local ethics committee, and all patients gave their written informed consent.

Laboratory measurements. Peripheral venous blood was collected in the non-fasting state into tubes containing EDTA at room temperature and centrifuged within $60 \mathrm{~min}$, which is sufficient to prevent increases in tHcy resulting from ex vivo generation of homocysteine by erythrocytes [20]. The plasma fraction was then transferred to plastic vials, stored at $-80^{\circ} \mathrm{C}$ and assayed in 1998. Free and protein bound tHcy concentrations are stable in serum or plasma for 10 years or more [21]. THcy was measured by fully automated HPLC with fluorescence detection, using sodium borohydride for reduction of disulfide bonds and monobromobimane for derivation of sulfhydryl groups [22]. Samples were analysed in 12 series. The interassay coefficient of variation, was calculated from values from a quality control sample included in each series and was $5.1 \%$. Reported values are based on single measurements. The GFR was estimated by measuring creatinine clearance in patients with diabetic nephropathy [23], and by calculating creatinine clearance using the Cockroft-Gault formula in patients with normoalbuminuria. $\mathrm{HbA}_{1 \mathrm{c}}$ was measured by HPLC (DIAMAT Analyser, Bio-Rad, Hercules, Calif., USA) (normal range in our laboratory is $4.1-6.4 \%$ ). Serum-creatinine concentration was assessed by a kinetic Jaffé method. UAER was measured by enzyme immuno assay from 24-h urine collections.

Genotype analysis. Genomic DNA was extracted from peripheral blood leukocytes. With reference to a recent publication [5] the MTHFR gene fragment of interest was amplified by PCR. The mutation was identified using the RFLP method by Hinf I digestion, which cuts at the mutation site, followed by agarose gel electrophoresis (1.5\% NuSieve 1:3 Agarose, FMC Bioproducts, Rockland, Me., USA) and ethidium bromide $(0.016 \% \mathrm{v} / \mathrm{v})$ fluorescence in reference to a molecular weight marker.

Statistical analysis. Genotype distribution, and allele frequency of the study groups were compared with the Chi-Square test, or Fisher's Exact test. The Hardy-Weinberg equilibrium was checked by Chi-Square test. The influence of GFR on 
tHcy was evaluated by simple regression analysis. Further influencing factors on tHcy concentration and tHcy tertiles were investigated by multiple regression and logistic regression analysis, respectively, introducing all those variables as independent variables, which showed an association with tHcy in the univariate correlation analyses. To eliminate the effect of renal function on the results, the following regression analyses were carried out separately in all patients with GFR greater than or equal to $75 \mathrm{ml} \cdot \mathrm{min}^{-1} \cdot\left(1.73 \mathrm{~m}^{2}\right)^{-1}$. For the evaluation of the relation of tHcy and the MTHFR gene polymorphism with diabetic vascular complications and hypertension, logistic regression analysis was done with hypertension, diabetic nephropathy, retinopathy, CHD, or CVD as dependent variables, introducing all those variables as independent variables, which showed an association with these complications in the univariate correlation analyses. Similarly, the measurements of systolic, and diastolic blood pressure were investigated with multiple regression analysis. A two-sided $p$ value of less than 0.05 was considered significant. All calculations were done using a commercially available program (StatView, SAS Institute, Cary, N.C., USA).

\section{Results}

The clinical characteristics of the study groups are summarized in Table 1.

Measurements of tHcy. Simple regression analysis with tHcy as a dependent variable and GFR as an independent variable showed that the correlation of both variables is inversed, and skewed $(p<0.0001$, OR 0.9 (95\% CI: 0.899-0.928), adjusted $\mathrm{R}^{2}$ 0.138). Our results suggest (Fig. 1), and simple regression analysis

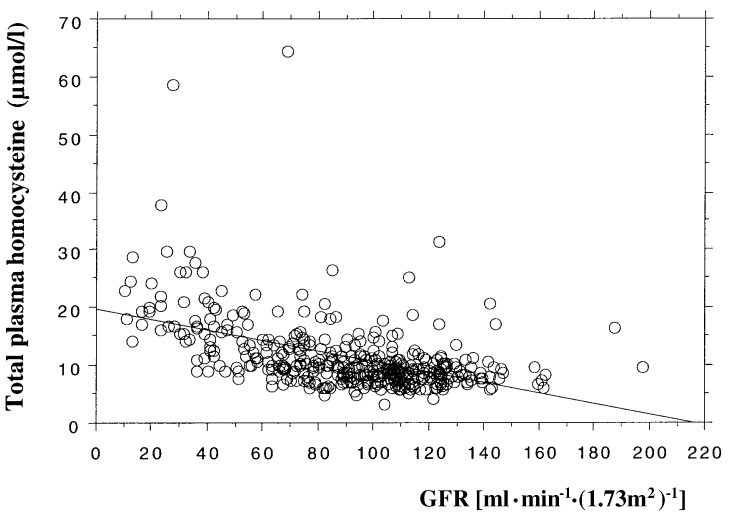

Fig. 1. GFR as a determinant of total plasma homocysteine. The bivariate scattergram with regression shows the relation between GFR and total plasma homocysteine in the study patients

confirms that a GFR-related increase of tHcy occurs only if the GFR decreases below the normal (= median) value of $75 \mathrm{ml} \cdot \mathrm{min}^{-1} \cdot\left(1.73 \mathrm{~m}^{2}\right)^{-1}$. Although there was no correlation of tHcy with GFR in patients with GFR greater than or equal to $75 \mathrm{ml} \cdot \mathrm{min}^{-1} \cdot\left(1.73 \mathrm{~m}^{2}\right)^{-1}$ $(p=0.1015$, OR 0.98 (95\% CI: 0.964-1.003), adjusted $\left.\mathrm{R}^{2} 0.063\right)$, simple regression analysis with data from patients with a GFR of less than $75 \mathrm{ml} \cdot \mathrm{min}^{-1}$. $\left(1.73 \mathrm{~m}^{2}\right)^{-1}$ showed an inverse linear correlation between tHcy and GFR $[p<0.0001$, OR $0.8(95 \%$ CI: 0.765-0.891), adjusted $R^{2}$ 0.169] (Fig. 2). Multiple regression analysis with GFR, MTHFR genotype, gender, and smoking as independent variables where

Table 1. Clinical characteristics of the study groups

Diabetic patients with GFR
$<75 \mathrm{ml} \cdot \mathrm{min}^{-1} \cdot\left(1.73 \mathrm{~m}^{2}\right)^{-1}$
$n=116$

Sex (men/women)

Age (years)

Diabetes duration (years)

BMI

$\mathrm{HbA}_{1 \mathrm{c}}(\%)$

Urinary albumin excretion rate $(\mathrm{mg} / 24 \mathrm{~h})$

Creatinine $(\mu \mathrm{mol} / \mathrm{l})$

GFR $\left[\mathrm{ml} \cdot \mathrm{min}^{-1} \cdot\left(1.73 \mathrm{~m}^{2}\right)^{-1}\right]^{\mathrm{a}}$

Total plasma homocysteine $(\mu \mathrm{mol} / \mathrm{l})$

Nephropathy (\%)

Retinopathy (simplex/proliferative) (\%)

Hypertension (\%)

Systolic BP (mmHg)

Diastolic BP (mmHg)

CHD (\%)

Cardiovascular disease (\%)

Smoking (\%)

$67 / 49$
$44.9[10.4]$
$29.5[9.2]$
$24.0[3.3]$
$9.5[1.6]$
$858(2-8824)$
$123(70-684)$
$52(10-74.9)$
$14.4(6.6-64.5)$
86
$97(25.8 / 71.6)$
91
$158[23]$
$87[14]$
28
38
38

\author{
Diabetic patients with GFR \\ $\geq 75 \mathrm{ml} \cdot \mathrm{min}^{-1} \cdot\left(1.73 \mathrm{~m}^{2}\right)^{-1}$ \\ $n=273$
}

a GFR was estimated by measuring creatinine clearance in patients with diabetic nephropathy and by calculating creatinine clearance with Cockroft-Gault formula in patients with normoalbuminuria
Measured data for urinary albumin excretion rate, creatinine, GFR, and total plasma homocysteine showed skewed distributions, and values are given as medians (range). All other values are given as means [SD] 

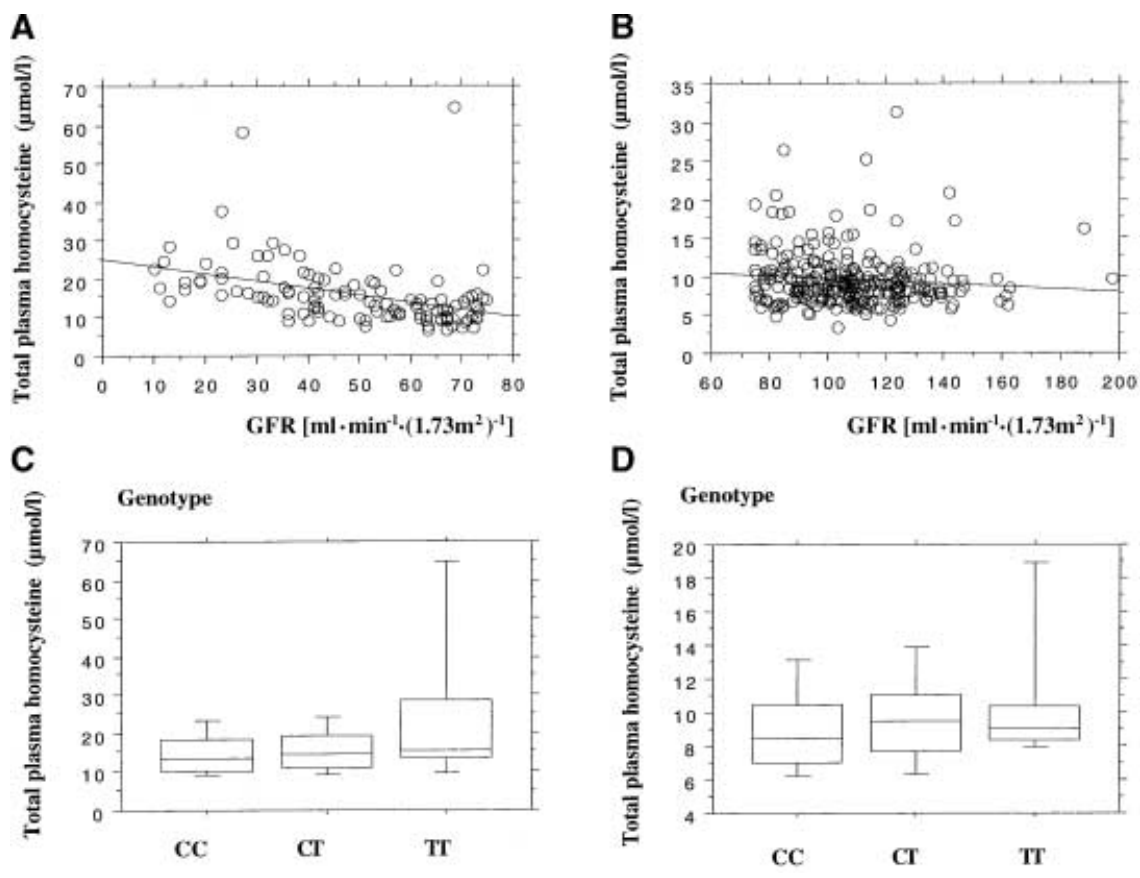

Fig. 2A-D. GFR and methylenetetrahydrofolate reductase genotype as determinants for total plasma homocysteine. The bivariate scattergrams $(\mathbf{A}, \mathbf{B})$ with regression show the relation between GFR and total plasma homocysteine, and the box plot diagrams $(\mathbf{C}, \mathbf{D})$ show $10^{\text {th }}, 25^{\text {th }}$, median $\left(50^{\text {th }}\right), 75^{\text {th }}$, and $90^{\text {th }}$ percentiles of total plasma homocysteine concentrations in relation to methylenetetrahydrofolate reductase genotype in patients with GFR $<75 \mathrm{ml} / \mathrm{min} / 1.73 \mathrm{~m}^{2}(\mathbf{A}, \mathbf{C})$, and GFR=75 ml/min $/ 1.73 \mathrm{~m}^{2}$ $(\mathbf{B}, \mathbf{D})$

MTHFR genotype, gender and smoking were enforced into the model showed that $20 \%$ of the variability of tHcy in patients with GFR less than $75 \mathrm{ml} \cdot \mathrm{min}^{-1}$. $\left(1.73 \mathrm{~m}^{2}\right)^{-1}$ were explained by the variability in GFR [OR 0.8 (95\% CI: 0.763-0.889); $p<0.0001]$ and MTHFR genotype [OR 2.5 (95\% CI: 1.327-4.641); $p=0.0048$; adjusted $\mathrm{R}^{2}$ 0.204] (Fig. 2). When logistic regression analysis was carried out exchanging tHcy with tHcy tertiles (low tertile: $=8.6 \mu \mathrm{mol} / 1$, middle tertile: $8.6-11.3 \mu \mathrm{mol} / \mathrm{l}$, upper tertile: $>11.3 \mu \mathrm{mol} / \mathrm{l})$, as dependent variables, it became obvious, that the TT genotype is a stronger determinant for tHcy [ $p=0.0083$, OR 4.2 (95\% CI: 1.447-12.179)], than the $C T$ genotype $[p=0.0321$, OR $2.0 \quad(95 \%$ CI: 1.056-3.376)] (Fig. 2). In patients with GFR greater than or equal to $75 \mathrm{ml} \cdot \mathrm{min}^{-1} \cdot\left(1.73 \mathrm{~m}^{2}\right)^{-1}$, however, MTHFR genotype [OR 1.2 (95\% CI: 1.022-1.354); $p=0.0229]$, male gender, and smoking contributed to a comparatively small risk for higher tHcy concentrations (adjusted $\mathrm{R}^{2}$ 0.063) (Fig. 2). Neither UAER nor $\mathrm{HbA}_{1 \mathrm{c}}$ or blood pressure were determinants of tHcy.

Total plasma homocysteine concentration as a determinant of blood pressure and hypertension. Median

tHcy concentrations were higher in patients with hypertension than in patients with normotension, also in patients with impaired and normal renal function (Table 2). However, tHcy was not a determinate of hypertension after the data of the whole study group were adjusted for GFR $(p=0.0612)$ [determinants: nephropathy, age $\left(\mathrm{R}^{2} 0.383\right)$ ]. Hypertension was only determinated by nephropathy $\left(\mathrm{R}^{2} 0.32\right)$ in diabetic patients with impaired renal function. Meanwhile, a logistic regression analysis (adjusted for GFR) with data from patients with a GFR greater than or equal to $75 \mathrm{ml} \cdot \mathrm{min}^{-1} \cdot\left(1.73 \mathrm{~m}^{2}\right)^{-1}$ (Table 2) provided evidence for a strong association of tHcy concentration of greater than $8.6 \mu \mathrm{mol} / \mathrm{l}$ (middle and upper tertiles) with an increased risk for hypertension. The association was independent from nephropathy [OR 10.4 (95\% CI: 5.321-20.151); $p<0.0001]$ and age [OR 1.05 (95\% CI: 1.017-1.098); $p=0.0036]\left(\mathrm{R}^{2}\right.$ 0.244). Patients with tHcy concentrations within the middle tertile $(8.6-11.3 \mu \mathrm{mol} / \mathrm{l})$ had a 1.98 times higher OR of hypertension (95\% CI: 1.008-3.871; $p=0.0474$ ), and patients with tHcy concentrations within the upper tertile had already a 3.7 times higher OR of hypertension, compared to those with tHcy concentrations of the lower tertile (95\% CI: $1.611-8.535 ; p=0.0021$ ).

Multiple regression analysis with systolic and diastolic blood pressure as dependent variables, showed that an increase of tHcy of $1 \mu \mathrm{mol} / \mathrm{l}$ is associated with a rise in systolic blood pressure of $0.9 \mathrm{~mm} \mathrm{Hg}$ (adjusted for age and GFR; $p=0.0024$, adjusted $\mathrm{R}^{2} 0.237$ ) and a rise of diastolic blood pressure of $0.4 \mathrm{~mm} \mathrm{Hg}$ (adjusted for age, GFR, and diabetes duration; $p=0.0153$, adjusted $R^{2} 0.126$ ), if all other independent variables remain constant (Fig. 3). There was also a positive relation between tHcy and pulse pressure $(p=0.0210$, ad- 

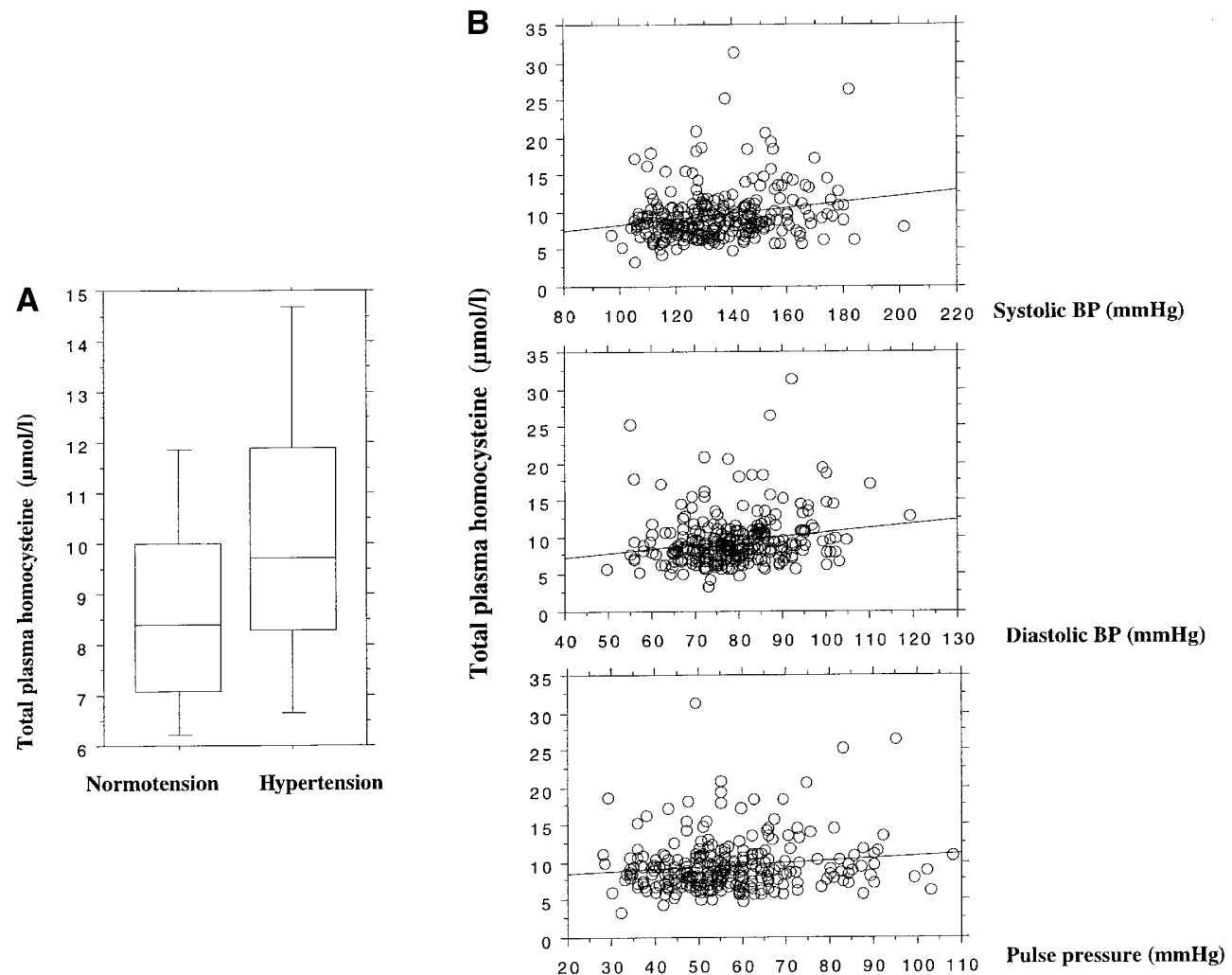

Fig. 3A, B. Total plasma homocysteine as determinant for hypertension and blood pressure in patients with normal renal function. The box plot diagram (A) shows $10^{\text {th }}, 25^{\text {th }}$, median $\left(50^{\text {th }}\right), 75^{\text {th }}$, and $90^{\text {th }}$ percentiles of total plasma homocysteine concentrations in patients with hypertension and normotension.

The bivariate scattergrams $(\mathbf{B})$ with regression show the correlation of total plasma homocysteine concentration with systolic $\mathrm{BP}\left(\mathrm{R}^{2}\right.$ 0.046), diastolic BP $\left(\mathrm{R}^{2} 0.033\right)$, and pulse pressure $\left(\mathrm{R}^{2}\right.$ 0.016), respectively. All data were obtained from patients with GFR=75 $\mathrm{ml} / \mathrm{min} / 1.73 \mathrm{~m}^{2}$

Table 2. Total homocysteine plasma concentration in relation to diabetic vascular complications and renal function

\section{All diabetic patients} $(n=389)$
Diabetic patients with

GFR <75 ml. $\mathrm{min}^{-1} \cdot\left(1.73 \mathrm{~m}^{2}\right)^{-1}$ $(n=116)$
GFR $\geq 75 \mathrm{ml} \cdot \mathrm{min}^{-1} \cdot\left(1.73 \mathrm{~m}^{2}\right)^{-1} \mathrm{a}$ $(n=273)$
Genotype

$\mathrm{C} / \mathrm{C}$

$\mathrm{C} / \mathrm{T}$

$\mathrm{T} / \mathrm{T}$

Hypertension

Normotension

Nephropathy

Normoalbuminuria

Retinopathy

proliferative

simplex

nil

CHD

No CHD

Cardiovascular disease

No cardiovascular disease

$$
\begin{gathered}
9.6(3.4-29.7) \\
9.8(4.3-58.5) \\
9.8(6.5-64.5) \\
11.7(5-58.5) \\
8.4(3.4-64.5) \\
11.4(5.0-58.5) \\
8.5(3.4-64.5)
\end{gathered}
$$

$$
\begin{array}{r}
9.0(3.4-26.5) \\
11.0(5.8-64.5) \\
9.3(5.8-31.4) \\
13.6(5.4-58.5) \\
9.5(3.4-64.5) \\
11.8(5.4-58.5) \\
9.5(3.4-64.5)
\end{array}
$$

$13.9(6.6-29.7)$
$14.4(7.5-58.5)$
$15.5(8.8-64.5)$
$14.6(7.7-58.5)$
$10.0(6.6-64.5)$
$14.6(7.7-58.5)$
$10.4(6.6-64.5)$

$14.6(7.8-64.5)$

$13.1(7.5-26.2)$

$6.7(6.6-7.4)$

$15.8(6.7-58.5)$

$13.3(6.6-64.5)$

$16.5(6.7-58.5)$

$13.0(6.6-64.5)$
$8.4(3.4-25.3)$

$9.4(4.3-26.5)$

$9.0(6.5-31.4)$

$9.7(6.1-20.6)$

$8.4(3.4-31.4)$

$9.6(5.0-19.5)$

$8.4(3.4-31.4)$

$9.0(5.8-19.5)$

$8.4(3.4-26.5)$

$9.3(5.8-31.4)$

$10.7(5.4-26.5)$

8.7 (3.4-31.4)

$9.5(5.4-26.5)$

8.7 (3.4-31.4) a A GFR of $\geq 75 \mathrm{ml} \cdot \mathrm{min}^{-1} \cdot\left(1.73 \mathrm{~m}^{2}\right)^{-1}$ (median) defines normal renal function. The correlation of tHcy values with GFR is inversed in patients with impaired renal function [GFR $<75 \mathrm{ml} \cdot \mathrm{min}^{-1} \cdot\left(1.73 \mathrm{~m}^{2}\right)^{-1}$ ], however not related to GFR in patients with normal renal function.
Total plasma homocysteine (tHcy) is expressed in $\mu \mathrm{mol} / \mathrm{l}$, data are given in median (range) 

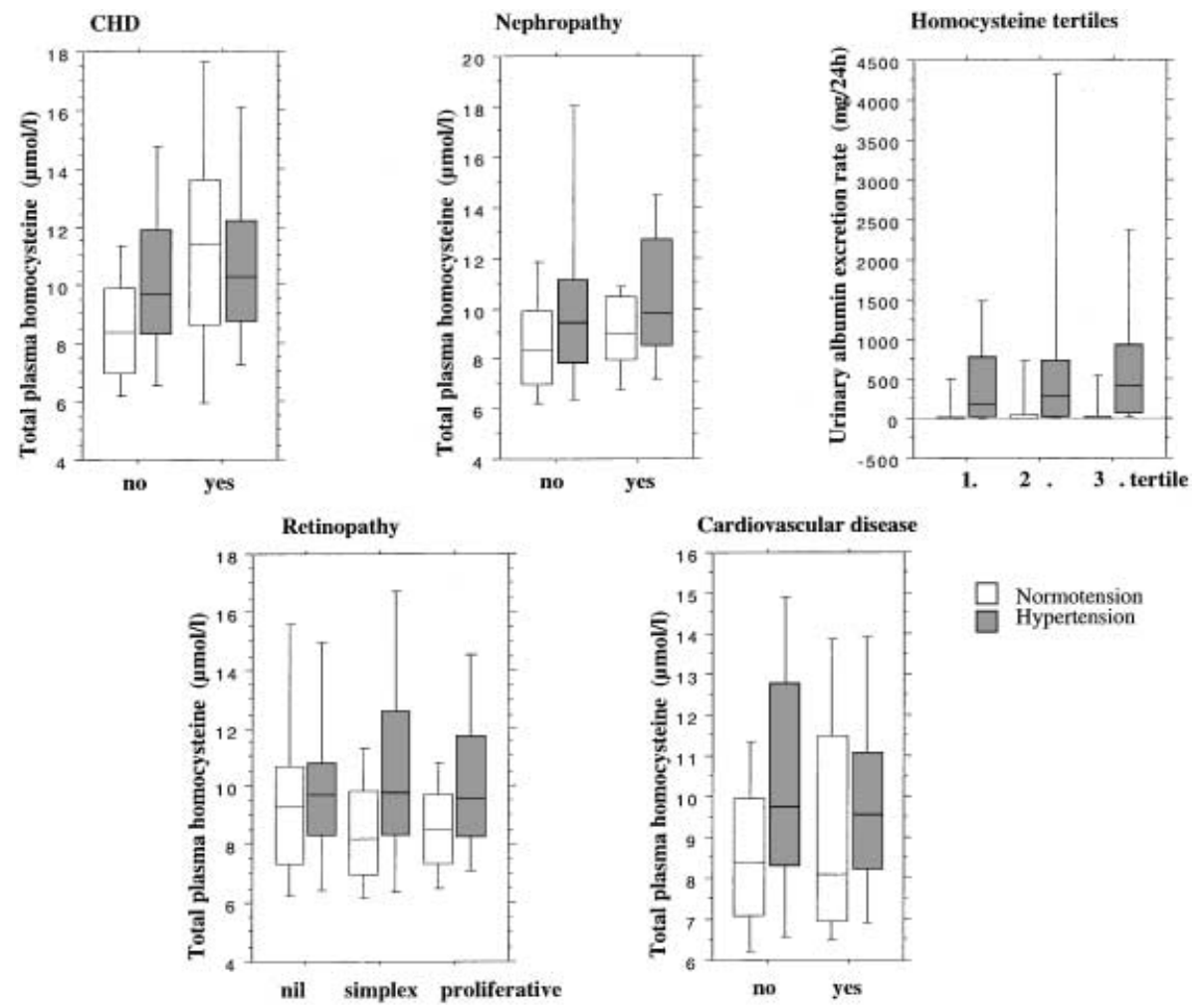

Normotension Hypertension

Fig. 4. Relation among total plasma homocysteine, hypertension and vascular complications in patients with normal renal function. The box plots show $10^{\text {th }}, 25^{\text {th }}$, median $\left(50^{\text {th }}\right), 75^{\text {th }}$, and $90^{\text {th }}$ percentiles of plasma homocysteine concentrations in patients with and without vascular complications in relation to hypertension. The correlations among proteinuria, total plasma homocysteine tertiles and hypertension are shown. All data were obtained from patients with GFR $\geq 75 \mathrm{ml} / \mathrm{min} /$ $1.73 \mathrm{~m}^{2}$

justed $\mathrm{R}^{2}$ 0.194) (Fig. 3). The MTHFR gene polymorphism did not contribute to the higher risk for hypertension.

Total plasma homocysteine concentration as a determinant of diabetic vascular complications. Patients with vascular complications showed higher tHcy concentrations than those without complications in both groups, with normal and impaired kidney function (Table 2). Total plasma homocysteine concentrations were generally higher in patients with impaired renal function (Table 2). Logistic regression analyses adjusted for GFR showed that increased tHcy concentrations do not predict diabetic microvascular and macrovascular complications either in the whole study group nor in patients with impaired renal function. The main determinant for those complications was hypertension.

Calculations with data of the group with normal renal function showed that the risk for CHD was enhanced by a tHcy concentration of more than
$11.3 \mu \mathrm{mol} / \mathrm{l}$ [OR 5.917 (95\% CI: 1.715-20.408); $p=0.0049]$, independently of other confounding factors, such as male gender [OR 2.926 (95\% CI: $1.101-7.775) ; p=0.0313]$, and diabetes duration [OR 1.094 (95\% CI: 1.028-1.164); $p=0.0049]$ ( $\left.\mathrm{R}^{2} 0.145\right)$. Increased tHcy concentrations found in patients with retinopathy, nephropathy or increased UAER, were related to hypertension, which is over-represented in the groups with microvascular complications (Fig. 4). There was no relation between tHcy and CVD, which was determinated by hypertension and diabetes duration.

Although the T allele was an independent determinant of tHcy, the MTHFR gene polymorphism was not associated with a higher risk for diabetic vascular complications after adjustment for other confounding factors.

Genotype analysis as a determinant of diabetic vascular complications. The Genotype distribution and allele frequency of the mutated $\mathrm{T}$ allele were different when diabetic patients with proliferative retinopathy were compared to patients without retinopathy, however, not significantly ( $p=0.056$ and $p=0.084$, respectively) (Fig. 5.). No association of the MTHFR gene polymorphism with nephropathy, CHD, CVD, or hypertension was detected (carriers: $47 \%, 51 \%, 52 \%$, and $48 \%$, respectively) (Fig. 5). 
A

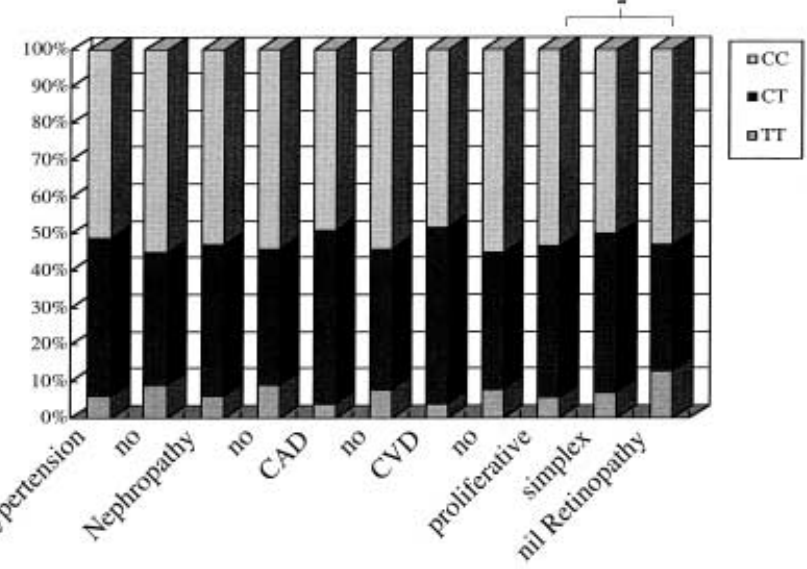

B

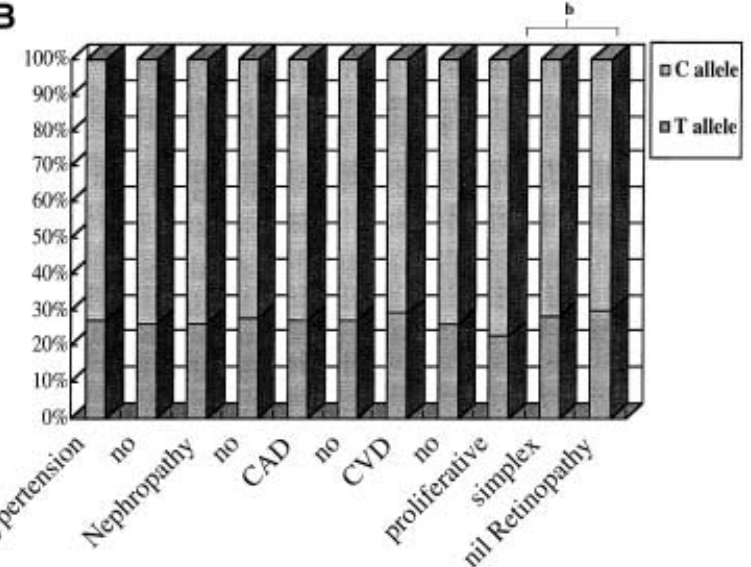

Fig. 5A, B. Genotype distribution and allele frequencies of the methylenetetrahydrofolate reductase gene polymorphism. Data from all patients with and without hypertension or vascular complications are shown. A Genotype distribution, and $\mathbf{B}$ allele frequencies. *Two tailed $p=0.0563$, **two tailed $p=0.0837$, not significantly different from patients with nil retinopathy

\section{Discussion}

This cross-sectional study with large groups of welldefined Type I diabetic patients provides evidence that tHcy confers increasing risk for hypertension in a dose-dependent manner in patients with normal GFR. Total plasma homocysteine concentrations lower than those generally defined as mild hyperhomocysteinaemia, are already associated with a twofold increase in risk for hypertension. Furthermore, systolic blood pressure, and to a lesser extent diastolic blood pressure, rise with increasing tHcy concentrations. There was also a positive association between tHcy and pulse pressure which is more closely linked to the structure and function of large arteries. Increased median tHcy concentrations in patients with microvascular complications express the higher prevalence of hypertensive patients, who have higher tHcy concentrations than normotensive patients. Thus our results suggest that modest hyperhomocysteinaemia could promote microvascular complications through enhancing the risk for hypertension. These findings support the results of the few previous investigations with mainly small sample sizes which also showed an association of mild hyperhomocysteinaemia with hypertension $[14,15]$, or systolic hypertension in non-diabetic patients [24], and with diastolic blood pressure in Type II diabetic patients [16]. Our results are also in line with those of very large cohort based investigations on non-diabetic subjects. The Hordaland study [25], and the UK National Diet and Nutrition Survey [26] observed an association of tHcy with blood pressure in subjects younger than 65 years of age, however only a weak relation between tHcy, and blood pressure in subjects older than 65 years. In none of the quoted studies, however, were data adjusted for GFR, which might have resulted in an underestimation of the relation between tHcy and blood pressure, as renal function declines with age, and long-standing hypertension.

Mild hyperhomocysteinaemia was also associated with nearly a sixfold higher OR of having CHD, independent of the strong cardiovascular risk factor hypertension. These results conform to those from the Hoorn study which could show that the OR for any cardiovascular disease was 2.33 per $5 \mu \mathrm{mol} / 1$ increment in tHcy in Type II diabetic patients [13]. It is also supported by large case-control studies on nondiabetic patients [27, 28]. The European Concerted Action Project [27], also showed that an increased fasting tHcy concentration multiplied the risk for cardiovascular disease in patients with hypertension.

Given the biological mechanisms proposed in support of the hypothesis that mild hyperhomocysteinaemia confers enhanced risk to CVD, a positive association with blood pressure seems to be the missing link. Results from experimental studies which showed that hyperhomocysteinaemia interferes with the vasodilator and antithrombotic function of nitric oxide [29, 30] and with the peroxide-mediated effects on arterial prostacyclin synthesis [31] were supported by clinical findings. Recently, an inverse relation between a range of tHcy concentrations and endothelium-dependent coronary blood flow was documented [32]. Furthermore, it was shown that increased tHcy concentrations in patients with essential hypertension are strongly and independently correlated to stiffness of the aortic artery measured by aortic pulse wave velocity (adjusted for GFR) [33]. Thus, longstanding, mild to moderate hyperhomocysteinaemia could contribute to the development of hypertension through interference with the nitrovasodilator system and could therefore promote microvascular and macrovascular complications, which are mainly determined by hypertension. However, as our study is cross-sectional, we have no direct evidence for a cause and effect interaction. 
It has been shown that the metabolism of tHcy in kidney tissue causes a major fraction of total renal clearance of tHcy, and it has been suggested that the loss of capacity for homocysteine degradation might explain the increase in tHcy seen in end-stage renal diseases [34]. Our study showed that an even modest deterioration of renal function, a GFR of less than $75 \mathrm{ml} \cdot \mathrm{min}^{-1} \cdot\left(1.73 \mathrm{~m}^{2}\right)^{-1}$, causes an increase of tHcy concentrations, whereas a GFR of more than or equal to $75 \mathrm{ml} \cdot \mathrm{min}^{-1} \cdot\left(1.73 \mathrm{~m}^{2}\right)^{-1}$ does not. It is important to note that the patients' tHcy concentrations increase sharply with values of GFR, which might still correlate with normal creatinine values. This might explain the conflicting results of the few investigations on the relation of tHcy with diabetic microvascular complications. Most of these studies considered the influence of renal function on tHcy to some extent, by matching the study groups for, or excluding patients with certain serum creatinine concentrations. Adjustment of the study results for GFR, the more sensitive predictor of renal function, however, has been done by only a few investigators recently. The association of increased tHcy concentrations with age [15], diabetic retinopathy [35], and nephropathy has been shown to be closely related to declining GFR below a normal value of $80 \mathrm{ml} \cdot \mathrm{min} \cdot\left(1.73 \mathrm{~m}^{2}\right)^{-1}[35,36]$. After adjustment for GFR, tHcy remained a strong predictor for CHD disease in normotensive Type II diabetic patients, but not for diabetic nephropathy [35, 36] or retinopathy [35]. Our data from a larger number of study patients confirms these findings.

Although tHcy concentrations were generally higher in patients with impaired renal function, there was no relation between tHcy concentrations and diabetic vascular complications or hypertension in this group. As hypertension, is such a potent risk factor for diabetic vascular complications in patients with impaired renal function, they might not confer any additive risk. A tHcy concentration of more than or equal to $8.2 \mu \mathrm{mol} / \mathrm{l}$, was reported to correlate to an increase of the 6-year all-cause mortality in Type II diabetic patients [37]. Therefore there is the possibility of survivorship effect on the outcome of the study.

Patients with classical inherited homocystinuria and hyperhomocysteinaemia suffer from atherosclerotic and thrombembolic complications in early adolescence. An increased tHcy level could cause structural vascular changes by enhancing endothelial cell injury $[4,11]$, platelet-mediated proliferation of smooth muscle cells, by affecting the coagulation system, and by contributing to the oxidative modification of LDL [4], as plausible pathogenetic mechanisms. It can also not be excluded that tHcy is an acute-phase reactant that is predominantly a marker of endothelial dysfunction, and of consecutive impaired homocysteine degradation. Such low tHcy concentrations which we found to be associated with blood pressure and hypertension and which were suggested to be associated with increased mortality in Type II diabetic patients [37], could express long-standing endothelial cell injury in response to biochemical stimuli, oxidative stress, or share stress caused by increased blood pressure.

Whereas the T allele of the MTHFR gene polymorphism was a determinant for tHcy concentrations, it did not predict hypertension, or vascular complications $[5,6,7,8,9]$. The impact of genetic risk factors on the development of diabetic vascular complications might vary among different ethnic groups and between Type I and Type II diabetic patients. The weak relation between genotype and phenotype in our study could also reflect inter-individual differences in susceptibility to various risk factors acting together in atherogenesis.

We did not provide data on the folate status of the patients. However, the influence of those data on the outcome of our study if any is likely to be marginal. Although evidence suggests a reduction of tHcy with high folate intake [28], evidence on the relation between folate status and tHcy concentration is inconsistent, and a low folate status is neither correlated to hypertension nor to CHD. It has been found that the folate concentration has to drop below $6.8 \mathrm{ng} / \mathrm{ml}$ to affect the geometric mean tHcy concentration in pooled homozygotes, and heterozygotes for the MTHFR gene polymorphism in subjects with normal renal function, whereas tHcy concentrations were $33 \%$ higher in a similar patients with end-stage renal failure, and a low normal folate status of less than $29.2 \mathrm{ng} / \mathrm{ml}$ [38]. This could indicate that GFR is a much stronger determinant for tHcy than folate. Whether the reported inverse relation between folate status and tHcy remains after adjustment of the data for GFR has yet to be evaluated.

To our knowledge, this is the first report on tHcy as a determinant of hypertension after data adjustment for the important confounder GFR in a well defined large cohort of Danish Type I diabetic patients. Even modestly increased tHcy concentrations powerfully increased the risk for hypertension, and in addition for CHD, independent of other risk factors. The finding confirmed that the GFR acts as a determinant for tHcy at even moderately impaired renal function and implies the necessity for future studies to evaluate the data on tHcy after adjustment for GFR. Given the high prevalence of hyperhomocysteinaemia in an apparently well-nourished cohort and the tendency for tHcy concentrations to increase with declining kidney function, modest effects of homocysteine on the risk for CHD, hypertension, and consequently for diabetic vascular complications will have profound implications for public health. The contribution of tHcy measurement in risk assessment and risk reduction strategies needs to be confirmed by data from randomized prospective controlled trials of tHcy lowering interventions. 
Acknowledgements. This study was supported by grants-in-aids from the Ministry of Education and from the Ministry of Health and Welfare, Tokyo, Japan. We appreciate the assistance of Ms. B.V. Hansen in conducting this study.

\section{References}

1. Borch-Johnsen K, Kreiner S, Deckert T (1986) Mortality of Type I (insulin-dependent) diabetes mellitus in Denmark. Diabetologia 29: 767-772

2. Borch-Johnsen K, Norgaard K, Hommel E et al. (1992) Is diabetic nephropathy an inherited disease? Kidney Int 41: 719-722

3. Quinn M, Angelico MC, Warram JH, Krolewski AS (1996) Familial factors determine the development of diabetic nephropathy in patients with IDDM. Diabetologia 39: 940-945

4. McCully KS (1996) Homocysteine and vascular disease. The discovery of hyperhomocysteinaemia as a major factor in the pathogenesis of arteriosclerosis offers new strategies and opportunities for prevention and treatment. Nat Med 4: 386-389

5. Frosst P, Blom HJ, Milos R (1995) A candidate genetic risk factor for vascular disease: a common mutation in methylenetetrahydrofolate reductase. Nat Genet 10: 111113

6. Neugebauer S, Baba T, Watanabe T (1997) Defective homocysteine metabolism as a risk factor for diabetic retinopathy. Lancet 349: 473-474

7. Vaccaro O, Perna AF, Mancini FP et al. (2000) Plasma homocysteine and its determinants in diabetic retinopathy. Diabetes Care 23: 1026-1027

8. Neugebauer S, Baba T, Watanabe T (1998) Methylenetetrahydrofolate reductase gene polymorphism as a risk factor for diabetic nephropathy in NIDDM patients. Lancet 352: 454

9. Noiri E, Taguchi JI, Nakao A, Fujita T (2000) MTHFR gene polymorphism as an exacerbation factor of diabetic nephropathy in Type 2 diabetes: analysis in Japanese male hemodialysis patients. Diabetes Care 23: 260

10. Hultberg B, Agardh E, Andersson A et al. (1991) Increased levels of plasma homocysteine are associated with nephropathy, but not severe retinopathy in type 1 diabetes mellitus. Scand J Clin Lab Invest 51: 277-282

11. Hofmann MA, Kohl B, Zumbach MS et al. (1998) Hyperhomocysteinemia and endothelial dysfunction in IDDM. Diabetes Care 21: 841-848

12. Hoogeveen EK, Kostense PJ, Eysink PED et al. (2000) Hyperhomocysteinemia is associated with the presence of retinopathy in type 2 diabetes mellitus: the Hoorn study. Arch Intern Med 160: 2984-2990

13. Hoogeveen EK, KostensePJ, Mackaay AJ et al. (1998) Hyperhomocysteinemia is associated with an increased risk of cardiovascular disease, especially in non-insulin-dependent diabetes mellitus: a population-based study. Arterioscler Thromb Vasc Biol 18: 133-138

14. Mendis S, Athauda SB, Naser M, Takahashi K (1999) Association of hyperhomocysteinemia and hypertension in Sri Lankans. J Int Med Res 27: 38-44

15. Araki A, Sako Y, Fukushima Y, Matsumoto M, Asada T, Kita T (1989) Plasma sulfhydryl-containing amino acids in patients with cerebral infarction and in hypertensive subjects. Atherosclerosis 79: 139-146

16. Fiorina P, Lanfredini M, Montanari A, et al. (1998) Plasma homocysteine and folate are related to arterial blood pres- sure in Type 2 diabetes mellitus. Am J Hypertens 11: 1100-1107

17. Wollesen F, Brattström L, Refsum H, Ueland PM, Berglund L, Berne C (1999) Plasma total homocysteine and cysteine in relation to glomerular filtration rate in diabetes mellitus. Kidney Int 55: 1028-1035

18. Tarnow L, Cambien F, Rossing P et al. (1995) Lack of relationship between an insertion/deletion polymorphism in the angiotensin I-converting enzyme gene and diabetic nephropathy and proliferative retinopathy in IDDM patients. Diabetes 44: 489-494

19. Tarnow L, Cambien F, Rossing $P$ et al. (1995) Insertion/ deletion polymorphism in the angiotensin I-converting enzyme gene is associated with coronary heart disease in IDDM patients with diabetic nephropathy. Diabetologia 38: 798-803

20. Ueland PPM, Refsum H, Stabler SP, Malinow MR, Andersson A, Allen RH (1993) Total homocysteine in plasma or serum: methods and clinical applications. Clin Chem 39: $1764-1779$

21. Savage DG, Lindenbaum J, Stabler SP, Allen RH (1994) Sensitivity of serum methylmalonic acid and total homocysteine determinations for diagnosing cobalamin and folate deficiencies. Am J Med 96: 239-246

22. Finkerstrand T, Refsum H, Kvalheim G, Ueland PM (1993) Homocysteine and other thiols in plasma and urine: automated determination and sample stability. Clin Chem 39: 263-271

23. Rossing P, Astrup AS, Smidt UM, Parving HH (1994) Monitoring kidney function in diabetic nephropathy. Diabetologia 37: 708-712

24. Sutton-Tyrrell K, Bostom A, Selhub J, Ziegler-Johnson C (1997) High homocysteine levels are independently related to isolated systolic hypertension in older adults. Circulation 96: $1745-1749$

25. Nygard O, Vollset SE, Refsum H et al. (1995) Total plasma homocysteine and cardiovascular risk profile. The Hordaland Homocysteine Study. JAMA 274: 1526-1533

26. Bates CJ, Mansoor MA, Pols J van der, Prentice A, Cole TJ, Finch S (1997) Plasma homocysteine in a representative sample of 972 British men and women aged 65 and over. Eur J Clin Nutr 51: 691-697

27. Graham IM, Daly LE, Refsum HM et al. (1997) Plasma homocysteine as a risk factor for vascular disease. The European Concerted Action Project. JAMA 277: 17751781

28. Stampfer MJ (1992) Prospective study of plasma homocyst(e)ine and risk of myocardial infarction in US physicians. JAMA 268: 877-881

29. Stamler JS, Slivka A (1996) Biological chemistry of thiols in the vasculature and in vascular-related disease. Nutr Rev 54: 1-30

30. Mutus B, Rabini RA, Staffolani R et al. (2001) Homocysteine-induced inhibition of nitric oxide production in platelets: a study on healthy and diabetic subjects. Diabetologia 44: 979-982

31. Starkebaum G, Harlan JM (1986) Endothelial cell injury due to copper catalyzed hydroxide-peroxide generation from homocysteine. J Clin Invest 77: 1370-1376

32. Schachinger V, Britten MB, Elsner M, Walter DH, Scharrer I, Zeiher AM (1999) A positive family history of premature coronary artery disease is associated with impaired endothelium-dependent coronary blood flow regulation. Circulation 100: 1502-1508

33. Bortolotto LA, Safar ME, Billaud E et al. (1999) Plasma homocysteine, aortic stiffness and renal function in hypertensive patients. Hypertension 34: 837-842 
34. Bostom A, Brosnan JT, Hall B, Nadeau MR, Selhub J (1995) Net uptake of plasma homocysteine by the rat kidney in vivo. Atherosclerosis 116: 59-62

35. Smulders YM, Rakic M, Slaats EH et al. (1999) Fasting and post-methionine homocysteine levels in NIDDM: determinants and correlations with retinopathy, albuminuria, and cardiovascular disease. Diabetes Care 22: 125 132

36. Davies L, Wilmshurst EG, McElduff A, Gunton J, CliftonBligh P, FulcherGR (2001) The relationship among homo- cysteine creatinine clearance, and albuminuria in patients with type 2 diabetes. Diabetes Care 24: 1805-1809

37. Stehouwer CDA, Gall MA, Hougaard P, Jakobs C, Parving HH (1999) Plasma homocysteine concentration predicts mortality in non-insulin-dependent diabetic patients with and without albuminuria. Kidney Int 55: 308-314

38. Bostom AG, Shemin D, Lapane KL et al. (1996) Folate status is the major determinant of fasting total plasma homocysteine levels in maintenance dialysis patients. Atherosclerosis 123: 193-202 